\title{
Latin American Immigrants' Adaptation Experiences in Korea: Cases of Migrant Workers with Professions in Culture and Entertainment Sectors
}

\author{
Jinsook Choi ${ }^{1}$ \\ ${ }^{1}$ Ulsan National Institute of Science and Technology, Republic of Korea \\ Correspondence: Jinsook Choi. E-mail: jschoi@unist.ac.kr
}

Received: September 26, 2017

doi:10.5539/ass.v13n12p1
Accepted: October 1, $2017 \quad$ Online Published: November 28, 2017

URL: https://doi.org/10.5539/ass.v13n12p1

\begin{abstract}
This paper explores the cultural adjustment experiences of Latin American migrating professionals in Korea. Two areas of studies on immigration are adopted to conceptualize the experiences of Latin American migrating professionals in Korea: transnationalism and racial reconstruction. I used qualitative interviews to examine Latin American migrating professionals' adjustment experiences in Korea. Latin American migrating professionals' experiences involving immigration to Korea are characterized by relatively short-term sojourns, isolation, and racial visibility in Korea. The result suggests that they use adaptation strategies to overcome isolation and to achieve the reformation of racial identity. This study will contribute to (1) theorizing transnationalism and the racial reconstruction of Latin American migrant workers, and (2) our understanding of Korean society's readiness to receive immigrants, through examining Latin American migrating professionals' experiences with Korean society and culture.
\end{abstract}

Keywords: immigration, Latin America, migrating professionals, Korea, racial identity, adjustment strategies

\section{Introduction}

\subsection{Immigrants in Korea}

Recent trends in studying immigration as a transnational phenomenon have emphasized exchanges and networks between immigrant groups and their home countries, focusing on the flow of capital, culture, and information that transcends national borders (Basch, Schiller, \& Blanc, 2005; Schiller \& Faist, 2010; Schiller, Basch \& Blanc, 1995; Kivisto, 2001). Korean society is not an exception when it comes to the formation of transnational societies around the world. The increased number of immigrants in Korea has resulted in a rapid increase in the number of studies on immigrants by Korean researchers over the past 10 years. South Korea (henceforth Korea) has imported a significant number of migrant workers since the early 1990s. As a result, the number of foreigners living in Korea, as of the end of 2016, totaled more than 1.8 million. This total represents about 3.6 percent of the total population of 49 million (Korean Immigration Service 2016). The number of foreigners in Korea has more than tripled since 1997, when the total was 386,972 .

Korean immigration researchers (Kim, 2008; Kim, 2009) have paid attention to conflicts and the adaptation process that immigrants experience while staying and settling in Korean society. In a study that compared Latin American immigrants in Korea with those in Japan (Joo 2012), the researcher focused on socio-cultural adaptation. As Joo (2012) pointed out, the number of Latin American immigrants is small compared with other immigrants in Korea. However, compared with other countries with immigrants, such as Europe, East Asian countries, including Korea and Japan, are known to be "countries of migrant worker sojourn and not true immigration" (Seol \& Skrentny, 2009, p. 579). Most scholars of immigration have focused on the integration of migrants, with many studies of immigration addressing the economy, the labor market, and policy (Joo, 2012). However, research is lacking on the factors that lead migrants to stay, according to Seol and Skrentyny (2009).

In addition, researchers have looked at what Koreans think about foreign workers and what workers, in turn, think about Korea (Han, 2003; Lee, 2001; Choi, 2009). The "socio-cultural adaptation" examined in these studies refers to adaptation to a unified Korean culture. Such an approach is based on the premise that immigrants must adapt to Korean society and culture, probably because these studies have been carried out mainly on unskilled workers, and it has been thought that adaptation is a "must, not a choice" as long as these workers are living in Korea (Kim, 2008, p.163). In other words, it is understood that the degree of adaptation of the foreign workers who constitute a part of the domestic labor market is important for Korean society and immigration policies.

As such, the studies on professional immigrants who work in Korea have paid attention to regional differences in foreigners' ways of living and adaptation, pointing out that the concept of "adaptation to Korean society" has been too broad. In studies on professional foreigners in Korea, Choi (2009) found that professionals and students asked for help from others when they experienced difficulties, whereas married immigrants and immigrant workers attempted to 
solve their difficulties by themselves. Thus, methods of adaptation are closely related to professional foreigners' social relationships.

Although studies on transnationalism and migrant workers used to focus on unskilled laborers, recently, numerous scholars came forward to examine professional workers' migration. The parties among expatriates, professional laborers, have broadened our understanding of migration and transnationalism in the era of a global network (Colic-Peisker, 2010; Croucher, 2012; Cranston, 2016 just to name a few). For example, Colic-Peisker (2010) investigated migrating career professionals who had spent extended periods of time in at least three countries. She contrasted with the transnationalism studies because these migrating professionals develop a form of transnationalism that transcends national and territorial affiliations. Croucher (2012) argued that culture is an area that needs to be better understood, as primarily studies focusing on the economics of migration or social networks exist, but relatively little exists about culture. She made clear that the status of the "migrant of privilege" exists not only due to the individual's own social and/or economic status but also due to the relationship between the home country and the host country. For example, many times the relation of colonialism is involved. In most cases of "transnationalism" documented in studies, the migration usually occurs from the Global South (colonized) to the Global North (colonizer's country). Cranston (2016) challenged the binaries of "global" and "local" to examine how corporations that employ foreign professionals are redefining the perception and representation of "global work," changing it from a "hardship" to an "opportunity."

I argue that exploring professional migrants' adjustment experiences in Korea is important because their experiences reflect Koreans' perceptions of the world and of themselves in the process of globalization. Although many studies of "sociocultural adaptation" generally dealt with an individual's adaptation to the host country's culture and institutional norms, their limitation was that they examined the adjustment of individual students. The challenge is seeing how migrating professionals as a group negotiate the terms of their relationship to Korea and to the workplace. When the professions are extremely diverse among Latin American professional migrants in Korea (e.g., soccer coach, soccer player, chef, Spanish teacher, musician), how do we look beyond the individuals' differences to reveal commonalities in how Latin Americans as a group tend to negotiate their presence in Korea?

To understand the negotiation of their presence in Korea, we need to look at how Latin Americans see themselves in a country where no racial classification exists to conceptualize the diverse ethnic and racial groups in Latin America. In a country such as the United States (US), where diverse immigrants reside, a new ethnic-racial mapping has occurred (Urciuoli, 1996; Tatar, 2008). Mexicans are not distinguished as a particular "race" in their home country; rather, they are assigned to racial categorization in the US, being called a "Hispanic" or "Latino" (Urciuoli, 1996). Meanwhile, Latin Americans are given the new racial position of "Latinos" in the US. Hence, Latinos have also come to perceive their own identity as a race in the US. For example, De Genova and Ramos-Zaya (2003) demonstrated that Latinos from various countries attempted hierarchical reassignment in a factory in Chicago in consideration of their U.S. racial classifications according to the meaning of U. S. citizenship. Leinonen (2012) demonstrated that White Americans are located in various domains of immigrant visibility in Finland. Likewise, when several ethnic and racial groups of Latin Americans come to Korea, they might locate themselves differently, according to how Korea sees them.

This study on migrating professionals will contribute to understanding the current transnational landscape in Korea and other countries and to understanding transnationalism and racial reconstruction. In the following, I describe the general characteristics of Latin American expatriates in Korea and the research subjects who participated in the interview I conducted.

\subsection{General Characteristics of Latin American Professional Migrants in Korea}

Even though migrating professionals may be defined according to their education and skill levels, the most complex issue is how to define and classify the various levels of skills that professional workers have. This difficulty exists because the criteria and basis for skills differ by country and industry. For example, because each field-information communication, finance, law, culture and art-has its own concept of skills, and because the degree of skill required is different in each country, comparing foreign professionals to Korean professionals is difficult. In addition, the system of higher education in each country may differ; thus, skill levels may vary depending on professionals' experience after their education, even though the classification of skill is usually made by education level. If the definition of professionals is narrowed simply to education and skill levels, because the number of Latin American professionals is low as a percentage of total foreign professionals, the number of Latin American professionals will rapidly drop. Furthermore, portraying the distinct characteristics of each country is practically difficult. Therefore, for this paper, we use the definitions in a study by Im and Song (2010), classifying types of professionals by their residence statuses according to the Korean immigration control regulations, for convenience sake. According to the Immigration Control Act of Korea, foreign technical professionals are classified in the E-1 to E-7 categories depending on their visa types. In addition, the employees of investment companies (D-8-1) and religions (D-6) should be included depending on the type of visa.

According to recent statistics, the number of Latin American professionals compared to the total number of foreign professionals. Professionals from Latin America who live in Korea account for only about $1 \%$ out of all migrant workers. The total number of documented foreign immigrants is 932,983, and among them, expatriates make up about 
5\%, whereas Latin American expatriates make up 1\% (Korean immigration service 2016). Most professional immigrants in Korea are from the US and Canada, with the majority of them being education-related workers. About $20.8 \%$ of men and about $4.9 \%$ of women from Latin America in Korea are professionals, with the average being 14\% of total Latin Americans in Korea. The distribution of professionals is concentrated mainly in the capital and metropolitan areas. Foreign professionals in southern areas are concentrated in Geoje, where heavy industries have developed because Latin American workers are residing there, especially Brazilian workers who have been sent out to shipbuilding-related companies. Even though technical guidance (E-4) is also an important part of the professions, it was excluded from the status survey, as not many workers enter Korea with this type of visa. Under these restrictions, then, the number of Latin American professionals living in Korea is not large, and a significant difference also exists in the population proportion depending on the country and occupation.

\section{Methods of the Study}

\subsection{Research Site and Methods}

This research was conducted with the purpose of obtaining general information about Latin American immigrants in Korea. Data collection was carried out through in-depth interviews with informants from July to October 2011. The subjects of the study included 23 Latin Americans who came to Korea through individual agencies or personal networks. The interview data of professionals sent to Korean companies on a large scale for short-term contracts, such as the Brazilian professionals concentrated mainly in Geoje, are excluded in this paper because these professionals are different from others in the sense that Brazilian companies hire them, whereas Korean companies hire others. In-depth interviews were carried out in Spanish or English, in the case of Brazilians, with 12 Latin American expatriates among them, and with the following procedures: expatriates in various fields were selected as a sample for one-on-one interviews. Interviews were carried out with Latin American professionals in and around the Gyeongsangnam-do area, including Busan, and especially in the Ulsan area, where mainly researchers live. However, interviews were also carried out with the professionals in the Seoul area because limiting the area would have made it difficult to collect enough varied cases. I found my interviewees through internet sites but also by using the snowball sampling method: through the networks of friends or those who had already participated in an interview.

The interviews were conducted with the goal of obtaining information about participants' experiences in Korea, and this goal was pursued specifically through combining structured and unstructured interviews. The structured interview questions were divided into five broad areas: (1) basic information, such as the age, residence status, and area of residence; (2) everyday life in Korea; (3) the networks in Korea; (4) the relationships among Korea, their home countries, and their positions; and (5) others. Their adaptation strategies were investigated by focusing on their experiences in everyday life in Korea and on their Korean relationships. Interviews were carried out in English with Brazilian professionals and in Spanish with other Latin American professionals. The duration of the interviews varied from one hour to two hours. I interviewed them at a coffee shop or at the lounges of their companies.

\subsection{Research subjects}

The subjects of this study were Latin Americans engaged in culture and art fields, such as sports and music, and in education, in such positions as professors and lecturers. They can all move freely between Korea and their home countries, and they reflect the cultural and economic globalization of Korea. The Latin American professionals whom we interviewed, who were cooks, musicians, and football players - that is, who came to Korea with the residence statuses of those in the arts and entertainment - had obtained their current jobs mainly through the advertising of companies and agencies. Of the remainder of those interviewed, the majority had entered Korea through private networks. Among all of the professionals interviewed, college lecturers and cooks particularly reported that they came to Korea after seeing advertisements from private companies.

Even though women are often said to seek marriage or settlement as immigrants in a society, the Latin American women were not the only ones who indicated such a trend (Kim 2009); some of the male professionals had also gotten married or settled in Korea. If they already had relationships with or wished to marry Koreans, a strong possibility existed that the migrant professionals would live in Korea. However, in most cases, except for the case of getting married to a Korean, they immigrated to Korea with the expectation of staying for only two or three years. However, they sometimes extended the period of stay for two to three years if they were satisfied with their workplaces, and in other cases, the informants occasionally decided to stay longer depending on whether they found various social services appropriate for living in Korea with their families.

Table 1. Overview of Interviewees

\begin{tabular}{ccccccc}
\hline \multicolumn{3}{c}{ Gender Nationality Age } & Occupation & Area of Residence $\begin{array}{c}\text { Duration } \\
\text { of Stay }\end{array}$ \\
\hline 1 & F & Mexico & 42 & Spanish Instructor (college) & Ulsan & 10 years \\
2 & F & Peru & 26 & Part-time Spanish Instructor & Busan & 1.5 years Married to a Korean \\
3 & F & Chile & 51 & Pastor & Busan & 25 years Married to a Korean \\
4 & M & Peru & 31 & Cook & Seoul & 1.4 years \\
\hline
\end{tabular}




\begin{tabular}{|c|c|c|c|c|c|c|c|}
\hline 5 & M & Mexico & 41 & Doctoral-level researcher & Seoul & 6 months & Married to a Korean \\
\hline 5 & M & Brazil & 23 & Football player & Ulsan & 1.6 years & \\
\hline 6 & $\mathrm{M}$ & Brazil & 31 & Physical trainer & Ulsan & 2 years & \\
\hline 7 & M & Mexico & 46 & Consultant in the Spanish-speaking company & Daegu & 20 years & Married to a Korean \\
\hline 8 & $\mathrm{M}$ & Ecuador & 35 & Musician & Jinju & 5 years & 8 and 9 are brothers \\
\hline 9 & M & Ecuador & 30 & Musician & Jinju & 5 years & \\
\hline 10 & M & Peru & 32 & Musician & Seoul & 4 years & 10 and 11 are cousins \\
\hline 11 & M & Peru & 31 & Musician & Seoul & 4 years & \\
\hline 12 & M & Peru & 29 & Musician & Seoul & 4 years & Friend with 10,11 \\
\hline
\end{tabular}

The only immigrants who communicated partially in Korean among the interviewees were the pastor from Chile, who has been living in Korea for 25 years, and the Spanish instructor from Peru. Both of them married Koreans and settled in Korea or at least have no plans to return to their home countries. However, other interviewees who had married Koreans were not necessarily able to speak Korean. They could speak English as well as Spanish, their mother tongues. Therefore, they do not learn Korean because they can communicate in English, but in many cases, they do not try to learn Korean because they are not planning to live in Korea permanently.

In this paper, I argue that immigration from Latin America should be viewed in a different way from that demonstrated in previous studies confined to immigration from Asia. Furthermore, as the immigration of unskilled workers has mainly been studied, studies on professional workers are relatively scarce. In its focus on the professionals among Latin American immigrants in Korean society, the aim of this paper is to investigate the relationship between Korea and Latin America by particularly looking at the professional immigrants' ways of experiencing Korean society.

\section{Result}

\section{1 "A Place just to stop by": The Migration Path to the Global Korean Labor Market}

Korea (or Japan) has been known to "import foreign workers while avoiding a multiethnic society" (Seol and Skrentny, 2009 , p. 588). However, empirical research revealed that, in fact, the majority of the informants for the survey agreed to allow migrant workers' settlement, although negative results were found regarding "whether Korea should become multiethnic society or not." However, as Seol and Skrentny (2009) further demonstrated, among 46 countries, Korea was the only country that expressed opposition to more restrictive immigration policies. Thus, public opinion does not reveal a hostile attitude toward immigrants, and this is not the main reason that foreigners do not stay in Korea.

A Peruvian working as a cook in a Peruvian restaurant in Seoul said that he was motivated to come to Korea because ever since his childhood, he had wanted to visit the continent of Asia someday to learn about it firsthand. At first, he did not think that going to Korea would be the start of a visit to Asia, but he obtained his current job in the restaurant and came to Korea after seeing a recruitment ad from a help-wanted column on a Korean website related to Latin America, which was called "Viva Latin." He came to Korea two years ago on a four-year contract, and he might stay in Korea a little longer if given the chance to do so; if not, he will go back to Peru.

Ricardo, ${ }^{1}$ a 31-year-old Brazilian physical coach, was recruited two years ago through the Ulsan Hyundai Tiger Football Club, a professional football team in Ulsan. Sport personnel, such as players or coaches, are normally scouted through international agents; however, Ricardo came to Korea through the introduction of a coach at Hyundai whom he knew personally. After knowing that the team would recruit a Brazilian coach, he did not hesitate to come to Korea, partly because the annual salary was high, and partly because he had wanted to visit Korea at least once. His particular profession is often called a "fitness specialist" or "physical trainer." In Brazil, professional football teams have such specialized coaches, who play important roles in this industry.

Many professional immigrants consider Korea to be a "place to go through." In particular, football players and physical trainers are thought to gravitate toward European teams if their skills are excellent. However, they do not think it is a bad idea to stay in Korea for a short time because their profession requires them to accumulate ability and experience. More than 200 professional football teams are in Brazil, whereas only 16 teams are in Korea. Four or five professional coaches are needed for each team, but even so, becoming a coach in Brazil is difficult if one's skills and experience are not strong enough. In addition, it is regarded as positive if the career and professional technology accumulated in Brazil can be used, but doing this is difficult because Korea's football culture is different from that of Brazil. Ricardo observed that Korean football players were required to run on the football ground longer than usual the next day after losing a game as a sort of "punishment," which is also considered "more reinforced training." However, Brazilian football players are physically trained as usual in preparing for the next game if they lost a game despite their best efforts.

Brazilian coaches and trainers have to "tolerate" the cultural differences as long as they are in Korea, keeping in mind

\footnotetext{
${ }^{1}$ Except for cases in which we were allowed to use real names, such as Ricardo, all of the names used in this paper are pseudonyms.
} 
that they will go back to their home country and establish themselves there. In this way, they adapt properly to the Korean sport culture while at the same time trying to use their professional knowledge, but within the limits that Korean society allows. Ricardo said, "If I were doing this job in Brazil, I would be able to work more 'freely.' I would be very forthright about expressing my opinion and would try to strengthen the players' physical strength in my own way. However, they do not want my way in Korea. I need to yield to some extent." Some coaches he knows left for Brazil prior to the expiration of their contracts. Ricardo is willing to consider a contract extension after he has fulfilled the terms of his contract, but, he noted, only if this is helpful to his career. He said that it would not be a major problem because he regards Korea as merely a place to stay for a short time, although accommodating the Korean hierarchy is difficult. By using such a strategy — that is, "maintaining an appropriate distance" — such professionals stay in Korea for two years or perhaps for as long as four years.

\subsection{Korean Hierarchy and Networks}

One of the cultural characteristics that Latin American professionals experience in Korean society is the hierarchical relationship in the workplace. This hierarchical relationship affects the social networks they can make with Koreans. For example, Ricardo described the relationships between Korean colleagues and their superiors as follows.

"The thing that is important in Korea seems to be age. There are a total of thirteen football clubs in K-League, and there were Brazilian coaches on nine of the teams last year. However, only five remain now. The others left for Brazil before the expiration of their contracts. They left Korea because they could not tolerate the cultural differences. It seems that what we think is important for a coach is different from what is emphasized in Korea. The value of Brazilian coaches was not recognized because of their age, and at the same time, their professional knowledge was not taken into account."

As a case in point, a 55-year-old trainer in a Korean football club is allegedly respected only because he is old and despite the fact that he has no "new techniques." Ricardo said he believes that simply being older is not good enough because trainers need to continue to study and acquire new skills. He said that Korea will probably end up with no good coaches if it continues to follow this path.

Ricardo said he thinks that his failure to command recognition in his workplace is due to his relative youthfulness, despite his professional knowledge and skills. For example, initiating a conversation with the head coach is difficult for him. The head coach calls Ricardo to tell him what he wants, and then, the meeting is ended. If Ricardo has something to tell the head coach and asks for a face-to-face meeting, he receives the answer of "later." It is evident that even professionals who come to Korea with professional knowledge of Brazilian football are constrained from doing what they want in Korean society, where authoritarianism is so strong.

Besides Korea's authoritative culture, another factor that causes difficulties in forming networks with Koreans is the difference in the concept of "friends." For example, Gloria (a Spanish contract professor, unmarried) has lived in Ulsan for 10 years but has no Korean friends. Her everyday life is extremely concentrated on her work. Because she has lived in Ulsan for so long, she thinks she has adapted to everything there, to some extent, and she is familiar with the life, area, and people in Ulsan; however, the Koreans with whom she is acquainted are her colleagues at work, and she does not often meet other Latin Americans because they are married. Meanwhile, Mexican communities have formed in Korea, but she does not attend the meetings often because they are held mainly in Seoul. The Latin Americans of her acquaintance who have jobs are all Spanish instructors at colleges, and some of them have come to Korea through private companies on short-term contracts (three to four months). In addition, a considerable number of the Mexican women around her live in Korea because they married Korean men, and most of them are housewives.

Most of the professionals form networks with people from their home countries; however, those who live in provincial cities cannot participate in the Latin American communities, which are concentrated mainly in Seoul. Gloria said, "If it were not for my work, living in Korea would be very hard for me. About $90 \%$ of my life is now associated with work. Time alone once a week is my only free time." To Gloria, relationships in the workplace consist of "keeping reasonable distance." This situation exists partly because the teachers do not have enough time with one another and thus have no opportunity to develop intimate relationships, and partly because Gloria's relationships with her colleagues have so far been related to work. In addition, she is not in the same ranking with her colleagues; she does not participate in administration or research as the Korean professors do. She is teaching Spanish only as a "native speaker," and her job has not changed for 10 years. For this reason also, she is treated differently from Koreans.

Gloria provided yet another reason why it is so difficult for her to make friends with her colleague professors even though she could have formed relationships with them because she had worked with them for so long. She added, "I've lived here for a long time, but things are as unfamiliar to me as before and my thought that I am a stranger has not changed." However, she said that her experience as a stranger changed when she began to attend a Catholic church. "At the moment I found a Catholic church, I felt I was accepted in Korean society." However, the Catholic church did not prove to be the place that could help her to form relationships permanently. She needed to participate in more activities than simply going to church every Sunday to maintain her relationships, and she naturally grew away from the church due to the limits of her Korean. She sought the possibility of socio-cultural adaptation in religious life, but religious institutions do not necessarily form social networks, as the relationships there tend to remain formal.

Among Latin American professional migrant workers, musicians usually rely on agencies and do not need much 
communication with Koreans. In many cases, the number of Koreans they know is very limited despite the fact that they have been in Korea for several years. In addition, we found that Latin American professionals do not see the necessity of social relationships in their community, as it is very limited. Not many Latin American lecturers exist, for instance, whereas English lecturers form virtual communities, including several cyber cafes, exchange and share information through them. In summary, Latin American professional immigrants, who are not large in number, have difficulty solving the problem of socio-cultural adaptation individually partly due to the language barrier and partly due to the difficulty with forming networks with other Latin Americans in Korea.

\subsection{Being "White” or "Indian”: Racial Reassignment of Latin Americans in Korea}

Aside from the aspect of social networks, another characteristic of Latin American professionals' immigration experience and adaptation strategies is that they newly recognize their own racial identity. In this section, we investigate how racial identity is recognized in Korea, focusing on those professional immigrants in Korea who are Spanish instructors and those who have culture and arts or entertainment residence visas. With the phenomenon of immigration, culture can now move freely across territories without being geographically limited. Immigrants move into territories with their own cultures and commercialize the new cultures. In this section, as one example, we look at cultural artists, especially those participants who play so-called "Indian music." In addition, we use the example of Latin American professionals related to Spanish education, who account for the largest number of immigrant professions except for the Brazilian professionals who are in the field of energy industries, examining their experience and the adaptation strategies they use in Korea.

Miguel, who worked mainly as a Spanish instructor in Korean high schools and colleges for about 20 years until he recently found another job, emphasized that he is still a "foreigner" even though he has lived in Korea for a long time. He pointed out that he cannot be treated as a White and that he does not belong to the visible category culturally speaking. Miguel also mentioned that he himself thinks that he is from the "West," but Mexico is not considered part of the West in Korea. He added that Koreans are "indifferent" to him. In other words, Mexicans are essentially "invisible" foreigners. In addition, Gloria, who was mentioned above, also relies on comparisons with Latin Americans from the countries around Mexico to help people to recognize her home country, Mexico. She said that Koreans are moderately knowledgeable about Mexico, adding that they would not know much about Guatemala. In other words, they are experiencing Korea by considering Mexico's position both in the world and in Korea.

Miguel married a Korean woman and has two children, and he is familiar with Korea - enough to say confidently, "I know all the history of Korean society over the past twenty years." He may think that he has assimilated into Korea after having lived there for 20 years, but he is not good at Korean because he did not really need to learn it. He continuously taught Spanish at high schools and colleges before recently obtaining a job as a Spanish-speaking consultant for a company in the city where he lives. According to him, he did not learn Korean because the schools instructed him to use only Spanish in school and class. After that, he had no opportunity to learn Korean, but he can live in Korea without any particular difficulty as an English speaker.

Erica, a Spanish instructor at a private foreign language institute in Busan, was a flight attendant in Peru, changing her occupation after she moved to Korea. She selected the job as a Spanish instructor because she could not use her other knowledge and skills in Korea. She married a Korean man and has lived in Korea for one and a half years, but her network includes only the instructors from Uruguay and Mexico whom she has met in the workplace. She could form a network with other Latin Americans, as she worked in a private foreign language institute. The Koreans of her acquaintance are her Korean family and students at the institute. She is proficient in English as well as in Spanish, and she is planning to work as an English teacher at an English kindergarten. She said, "As I am a white, I will have no problem even though I become an English teacher," adding that it would be easier for a "White" to find a job than a "Latin American." In recognizing the concepts of racial identity in Korea, Erica understands well that racial reassignment is beneficial in the professional labor market.

In contrast with the above so-called "invisibility" that education professionals experience, the musician participants are visible, as they use indigenous costumes to reproduce aboriginal culture in performances and at folk flea markets. Their employment status is also relatively unstable compared with that of education or other professionals. They can work a total of only about eight months out of a year because they offer mostly outdoor performances mainly at stations, festivals, and regional events, and there are fewer jobs in the winter. The two groups of musicians whom the researcher met are made up of brothers from Ecuador and Peru and one friend, and cousins and two friends, respectively. They came to Korea with their brothers or cousins and are living together in Korea.

Luis (who has stayed in Korea for five years) is an Ecuadorean Andes performing musician in Korea. His group is composed of three people, including one friend and one brother. He brought his wife and daughter to Korea, and they sell Ecuadorean handcrafts when playing music at festivals and other events in addition to performing their musica native (native music). He vaguely dreamed of returning to his home country, saying "It is five years since I have lived here. Won't we be able to go back to our home country (para alla) within one or two years?" Before coming to Korea, they played music in other countries as well as in their home country. Luis even played in Europe for three years but went back to his home country owing to problems with living expenses. They contacted an advertising agency after seeing an advertisement seeking "Latin American performing musicians" and then came to Korea. 
Luis plays Andean music in a designated place at regional festivals. In addition to performing the music, he also sells Ecuadorean musical instruments, costumes, and handcrafts in a small shop. He is not good at speaking Korean, but his wife has learned Korean better because she is the main one who runs the shop, and she needs to speak Korean when she sells handcrafts. In this regard, they have chosen the "essential" adaptation to Korea, like the unskilled workers discussed by Kim et al. (2008). They are living by adapting to Korea's cultural market through the commercialization of their own culture and by adapting to the way of life by learning Korean. Like most of the musicians, they visit their home country during the slow season each year, bringing back Ecuadorean handcrafts each time they return to Korea.

When Latin American musicians deliver musical performances at subway stations or railroad stations, as well as at various events or festivals, and reproduce a part of indigenous culture, like "Andean music," they do this to reproduce indigenousness in the Korean context. Korean society sees "native Latin Americans" simply as "Indians," even when they play music in Apache Indian costumes, and the distinction between North America and South America is not deemed important. In this case, the cultural identity is relatively clear, compared with the vague positioning of Latin Americans. That is, Latin Americans are not considered to be "Whites" in Korea, such as Miguel or Gloria, as they regard Mexicans. Therefore, Koreans as "visible" or "marked" immigrants compared with Anglo-Americans. The immigrants' visibility is subject to each country and to the relationship between the host country and the migrants' country, as Leinonen (2012) showed in her study of white American expatriates in Finland. For example, White Americans are located in various domains of immigrant visibility in Finland-for example, with one domain including those who are visually identified as immigrants - and at the level of public and academic discussions on immigration.

In this respect, musicians differ from other Latin American professionals in Korea, who recognize their positions as "being invisible" in many cases. The musicians are regarded rather as "being visible" because they professionally take charge of informing Koreans about their own culture in the public space. Nevertheless, in reality, musicians actually can be more "invisible" than the professionals in charge of Spanish education are because the range of their activities in Korea is extremely limited except for their performances.

\section{Conclusions}

Despite the fact that a need for or interest in foreign professionals in Korea is currently increasing, empirical studies on this topic are scarce thus far. The aim of this paper is to describe Latin American professional immigrants' experiences and the adaptation strategies in Korea, by means of in-depth interviews, unlike the generalizations made in previous studies on foreign professionals. As a result of an investigation into the type of relationship that Latin American professionals have with Korea's sociocultural characteristics in their immigration experiences, it was found that they employ adaptation strategies, such as the formation of limited social networks and the reconstruction of their racial identity.

Unlike previous studies on immigration that have focused on immigrants from Asia and unskilled workers (Kim \& Oh, 2012), this study showed that Latin American professionals experience Korean society in a relatively different way and that how they express themselves also involves distinct characteristics. For those involved mainly in organizational life, such as in sports, the Latin American professionals who are not familiar with the Korean hierarchy perceive a cultural difference. In addition, making social networks is difficult for them. The education-related professionals have difficulty with forming networks because they are categorized as "temporary employees" in comparison with Korean professors, no matter how long they have worked. Musicians suffer from a lack of job security and have occupational characteristics that make it difficult for them to construct networks outside of close relationships with their managers. In addition, they participate in the commodification of the racial identity that Koreans have constructed. I attempted to illuminate looking at the adaptation of the Chinese students to British education systems, by illustrating how the professional immigrants as a 'group' negotiate the terms of their relationship to Korea and to their workplace.

The history of exchanges between Korea and Latin America is not long, and they have no shared culture due to the physical and cultural distances between the two countries (Joo, 2012; Ortiz, 2011; Kwak 1998). However, with the increasing trade with Latin America owing to Korea's recent global strategies, more transnational mobility might increase, occupying various areas of professions in Korean society. This study has limitations in terms of limited data, mostly from qualitative interview. Future studies should include more professionals from other occupations in the future. In addition, a comparison between professional immigrants from Latin America with those from other countries may lead to a better understanding of Korea's transnational landscape in this global era.

\section{Acknowledgements}

This work was supported by the Korean Institute of Economic Policy (KIEP) and the Presidential Research Fund (project No. 1.170066) of the Ulsan National Institute of Science \& Technology (UNIST).

\section{References}

Basch, L., Schiller, N. G., \& Blanc, C. S. (Eds.). (2005). Nations unbound: Transnational projects, postcolonial predicaments, and deterritorialized nation-states. London: Routledge. https://doi.org/10.4324/9780203347003

Choi, B. (2009). Hankuk ijunodongjaui ilteowa ilsangsenghwalui gonkanjuk teukseong (The spacial characteristics of daily lives of foreign workers in Korea). Journal of the economic geographical society of Korea, 12(4), 319-343. https://doi.org/10.23841/egsk.2009.12.4.319 
Colic-Peisker, V. A. L. (2010). Free floating in the cosmopolis? Exploring the identity-belonging of transnational knowledge workers. Global networks, 10(4), 467-488. https://doi.org/10.1111/j.1471-0374.2010.00298.x

Cranston, S. (2016). Imagining global work: Producing understandings of difference in 'easy Asia.' Geoforum, 70, 60-68. https://doi.org/10.1016/j.geoforum.2016.02.008

Croucher, S. (2012). Privileged mobility in an age of globality. Societies, 2(1), 1-13. https://doi.org/10.3390/soc2010001

De Genova, N., \& Ramos-Zayas, A. Y. (2003). Latino racial formations in the United States: An introduction. The Journal of Latin American and Caribbean Anthropology, 8(2), 2-16. https://doi.org/10.1525/jlca.2003.8.2.2

Han, K. S. (2003). Making other: Representation of foreign migrant workers in Korea. Comparative Cultural Research, 9(2), 157-193.

Im, S., \& Song, J. (2010). Urinaraui Oekukin Junmunjik Ijuja Heonghwangkwa Jirijuk Bunpo Teuksung (The Situations and the Geographic Distribution of Professional Foreign Laborers in Korea). Journal of Korean Association of Regional Geographers, 16(3), 275-294

Joo, J. (2012). Migration processes and sociocultural adaptation of Latin American migrant workers in Korea and Japan. Asian Journal of Latin American Studies, 25(1), 113-143.

Kim, A. E. (2009). Global migration and South Korea: Foreign workers, foreign brides and the making of a multicultural society. Ethnic and Racial Studies, 32(1), 70-92. https://doi.org/10.1080/01419870802044197

Kim, H. R., \& Oh, I. (2012). Foreigners cometh! Paths to multiculturalism in Japan, Korea and Taiwan. Asian and Pacific Migration Journal, 21(1), 105-133. https://doi.org/10.1177/011719681202100105

Kim, S. J. (2008). Oekukin nodongjaui munwhajeok galdungkwa daeung: Indonesiareul junsimuro, Minjokmunwhanonchong, 38, 153-184.

Kivisto, P. (2001). Theorizing transnational immigration: a critical review of current efforts. Ethnic and racial studies, 24(4), 549-577. https://doi.org/10.1080/01419870120049789

Kwak, J. (1998). Changing relationships between Asia and Latin America: Redefining the Pacific Rim. Asian Journal of Latin American Studies, 11, 1-16.

Leinonen, J. (2012). Invisible immigrants, visible expats?: Americans in Finnish discourses on immigration and internationalization. Nordic journal of Migration Research, 2(3), 213-223. https://doi.org/10.2478/v10202-011-0043-8

Ortiz, M. E. R. (2011). El acercamiento de México a Asia Pacífico. Hacia la firma de un Acuerdo con la República de Corea y un balance del Acuerdo de Asociación Económica con Japón. Asian Journal of Latin American Studies, 24(1), 29-52.

Schiller, N. G., Basch, L., \& Blanc, C. S. (1995). From immigrant to transmigrant: Theorizing transnational migration. Anthropological Quarterly, 68(1), 48-63. https://doi.org/10.2307/3317464

Schiller, N. G., \& Faist, T. (Eds.). (2010). Migration, development, and transnationalization: a critical stance: Vol. 12. New York, NY: Berghahn Books.

Selmer, J. (2006). Language ability and adjustment: Western expatriates in China. Thunderbird International Business Review, 48(3), 347-368. https://doi.org/10.1002/tie.20099

Seol, D. (1999). Oekukin nodongjawa hankuksahoe (Foreign laborers and Korean society, 1987-1998). Seoul, Korea: Seoul National University Press.

Tatar, B. (2008). Latino ethnicity and other influences on the immigrants' rights movement in the United States. American Studies, 31(1), 57-92. https://doi.org/10.18078/amstin.2008.31.1.003

Urciuoli, B. (1996). Exposing prejudice: Puerto Rican experiences of language, race, and class. Boulder, CO: Westview Press.

Vidal-Ortiz, S. (2004). On being a white person of color: Using autoethnography to understand Puerto Ricans' racialization. Qualitative Sociology, 27(2), 179-203. https://doi.org/10.1023/b:quas.0000020692.05355.6e

Wang, X. (2002). Expatriate adjustment from a social network perspective: Theoretical examination and a conceptual model, cross cultural management, 2(3), 321-337. https://doi.org/10.1177/147059580223003

\section{Source from Institutions}

Korean Immigration Service (2016). Tongkyeyunbo (National Statistical Data)

\section{Copyrights}

Copyright for this article is retained by the author(s), with first publication rights granted to the journal.

This is an open-access article distributed under the terms and conditions of the Creative Commons Attribution license (http://creativecommons.org/licenses/by/4.0/). 